\title{
Uptake of carbamazepine by rhizomes and endophytic bacteria of Phragmites australis
}

\section{Andrés Sauvêtre and Peter Schröder*}

Plant Endophyte Physiology, Research Unit Microbe-Plant Interactions, Helmholtz Zentrum München GmbH, German Research Center for Environmental Health, Munich, Germany

\section{Edited by:}

Antonella Furini, University of Verona, Italy

\section{Reviewed by:}

Muhammad Afzal, National Institute

of Biotechnology and Genetic

Engineering, Pakistan

Josep Maria Bayona, Consejo

Superior de Investigaciones

Cientificas, Spain

*Correspondence:

Peter Schröder, Plant Endophyte Physiology, Research Unit

Microbe-Plant Interactions, Helmholtz Zentrum München GmbH, German

Research Center for Environmental Health, Ingolstädter Landstraße 1, D-85764, Neuherberg, Germany e-mail: peter.schroeder@helmholtzmuenchen.de
Carbamazepine is an antiepileptic and mood-stabilizing drug which is used widely in Europe and North America. In the environment, it is found as a persistent and recalcitrant contaminant, being one of the most prominent hazardous pharmaceuticals and personal care products in effluents of wastewater treatment plants. Phragmites australis is one of the species with both, the highest potential of detoxification and phytoremediation. It has been used successfully in the treatment of industrial and municipal wastewater. Recently, the identification of endophytic microorganisms from different plant species growing in contaminated sites has provided a list of candidates which could be used as bio-inoculants for bioremediation of difficult compounds. In this study, Phragmites australis plants were exposed to $5 \mathrm{mg} / \mathrm{L}$ of carbamazepine. After 9 days the plants had removed $90 \%$ of the initial concentration. Endophytic bacteria were isolated from these plants and further characterized. Phylogenetic analysis based on 16S rDNA sequencing revealed that the majority of these isolates belong to three groups: Proteobacteria, Actinobacteria, and Bacteroidetes. Carbamazepine uptake and plant growth promoting (PGP) traits were analyzed among the isolates. Ninety percent of the isolates produce indole acetic acid (IAA) and all of them possess at least one of the PGP traits tested. One isolate identified as Chryseobacterium taeanense combines good carbamazepine uptake and all of the PGP traits. Rhizobium daejeonense can remove carbamazepine and produces $23 \mu \mathrm{g} / \mathrm{mL}$ of IAA. Diaphorobacter nitroreducens and Achromobacter mucicolens are suitable for carbamazepine removal while both, Pseudomonas veronii and Pseudomonas lini show high siderophore production and phosphate solubilization. Alone or in combination, these isolates might be applied as inoculates in constructed wetlands in order to enhance the phytoremediation of carbamazepine during wastewater treatment.

\section{Keywords: pharmaceuticals, carbamazepine, common reed, rhizomes, endophytic bacteria, phytoremediation}

\section{INTRODUCTION}

Daughton and Ternes (1999) first described the occurrence and significance of pharmaceuticals and personal care products (PPCPs) in the environment. They postulated the necessity of developing environmental risk assessment strategies for these substances in addition to the traditional priority pollutants (Daughton and Ternes, 1999). Since then, pharmaceuticals in the aquatic environment have raised increasing interest as it is reflected in the growing number of publications related to their fate (FattaKassinos et al., 2011). Although their concentrations may presently be low, their persistence and bioaccumulation will increasingly cause problems for drinking water quality in the future.

Belonging to this group, carbamazepine is one of the most problematic compounds in wastewater treatment plants (WWTPs). Widely used as antiepileptic and mood stabilizer since the 1970s, this pharmaceutical and its metabolites have commonly been detected in sewage and surface water (Ternes, 1998; Heberer et al., 2002; Tixier et al., 2003; Wiegel et al., 2004). The presence of carbamazepine has also been reported in groundwater (Lapworth etal., 2012) and drinking water as well (Huerta-Fontela et al., 2011). In fact, carbamazepine can reach groundwater without degradation during the soil-aquifer passage (Ternes et al., 2007).
Studies considering influent and effluent PPCPs concentration data from over 40 published sources corresponding to more than 40 pilot and full-scale wastewater treatment facilities have listed carbamazepine as one of the most recalcitrant PPCPs to removal via traditional wastewater treatment (Miège et al., 2009; Oulton et al., 2010). In none of these cases, the removal efficiency exceeded $30 \%$. Because of its persistence, carbamazepine has been applied as an indicator for urban influence on water systems (Strauch et al., 2008).

The rising number of pharmaceutical prescriptions for the aging population results in a higher discharge of the medicaments and their metabolites in sewage water. Subsequently, the presence of pharmaceuticals in surface waters has increased in recent years and it has been accepted that this tendency will continue in the near future. Efficient cleaning systems are needed to avoid or at least to reduce the intrusion of these compounds in our surface and groundwater systems, thus maintaining a high level of drinking water quality. The use of constructed wetlands as final polishing step in WWTPs or as sole treatment in small communities can constitute a good solution for recalcitrant compounds (Verlicchi and Zambello, 2014). If not completely, these systems have shown to reduce significantly the concentration of carbamazepine in the 
final effluent (Conkle et al., 2008; Matamoros et al., 2008, 2009; Park et al., 2009).

Evidence for the uptake of carbamazepine in different plant species is available from current literature (Herklotz et al., 2010; Winker etal., 2010; Wu et al., 2010, 2012; Shenker et al., 2011; Holling etal., 2012; Tanoue etal., 2012). Carbamazepine has been reported to be taken up and translocated into the aerial plant part, where it can be accumulated or metabolized to secondary products (Dordio et al., 2011). Macrophytes are a well suitable for water cleaning because of their ability to grow in flooded conditions and therefore they are generally used in constructed wetlands of water treatment facilities. Among them, Phragmites australis has been successfully utilized for phytoextraction of several xenobiotics including pharmaceuticals (Matamoros etal., 2005; Hijosa-Valsero etal., 2010; Carvalho etal., 2012).

In this context it is of high interest, that plant associated bacteria can aid plants to cope with stress resulting from exposure to xenobiotics. In recent years, plant endophytes capable of degrading xenobiotics have been isolated. Most of the studies focus on organic pollutants such as petroleum derivatives, PAHs, TCE, organochlorines, naphthalene, pyrene, or phenolic compounds (Siciliano et al., 2001; Aken et al., 2004; Germaine et al., 2006, 2009; Sheng et al., 2008; Weyens et al., 2009a, 2010; Yousaf et al., 2011; Ho et al., 2012; Kang et al., 2012; Peng et al., 2013). In re-inoculation experiments, some of these strains have improved remediation, favoring the metabolism of these compounds as well as the fitness of the plant (Afzal et al., 2014). However, research on the degradation of pharmaceuticals by endophytic microorganisms is scarce. Only bacteria from activated sludge in a municipal or ligninolytic fungi have been tested for carbamazepine degradation (Santos et al., 2012; Li et al., 2013).

Currently, carbamazepine uptake is thought to proceed via non-selective diffusion across the membrane and posterior translocation inside the plant (Winker etal., 2010). Therefore, the first steps of detoxification could be achieved by the endophytic community living in the roots and rhizomes of these aquatic plants. Our work aims at elucidating the cooperative uptake and degradation mechanisms of carbamazepine in Phragmites australis and its endobacteria and tries to give recommendations for its enhanced removal by phytoremediation. The objectives were to determine the uptake of the compound into the plant, to optimize a method for extraction of endophytic bacteria, to characterize the most abundant isolates and to assay their potential role in carbamazepine metabolism and plant growth promotion.

\section{MATERIALS AND METHODS PLANT MATERIAL}

Phragmites australis plants were supplied from a local grower (Jörg Petrowski, Eschede, Germany). In order to prepare them for the experiments, shoots were cut above the hypocotyl. Root systems (consisting of primary and secondary roots and rhizomes) were carefully washed in tap water to remove any attached soil, placed in individual pots containing perlite and grown in semi-hydroponic conditions at the Helmholtz Zentrum Muenchen, Bavaria, Germany. Greenhouse conditions were set to a light cycle of 16 h day and $8 \mathrm{~h}$ night, temperature of $25^{\circ} \mathrm{C}$ and $\mathrm{RH}$ of $60 \%$. Plants were grown in trays (six pots per tray) in modified Hoagland solution. After 8 weeks, when new biomass had developed, plants of uniform size were selected and placed into individual pots containing $2 \mathrm{~L}$ of modified Hoagland solution. To study carbamazepine uptake, a stock solution of carbamazepine (Sigma-Aldrich) in ethanol was added to each pot to a final concentration of $5 \mathrm{mg} / \mathrm{L}(21.16 \mu \mathrm{M})$. Controls containing only perlite were set up to investigate photodegradation, volatilization, adsorption on the plastic pot walls, or hydrolysis. Three pots were set up for each of the four exposure times $(0,1,4$, and 9 days) in the greenhouse and each assay consisted of three replicates, arranged in a completely randomized design. Distilled water was added daily to compensate losses by evapotranspiration (Dordio et al., 2011). Samples were taken at 0, 1,4 , and 9 days of exposure and immediately frozen at $-20^{\circ} \mathrm{C}$.

\section{CARBAMAZEPINE ANALYSIS}

Carbamazepine concentration in plant nutrient solutions was determined by high performance liquid chromatography (HPLC), using a Varian ProStar HPLC system (Varian ProStar 215 solvent delivery module, autosampler Prostar 410). All samples were prepared in triplicate. Plant nutrient solution samples were filtered using $0.45 \mu \mathrm{m}$ pore size polyvinylidene fluoride filters (Rotilabo, Carl Roth) before injection. Injection volume was $40 \mu \mathrm{L}$. The separation was performed on a C18 ProntoSIL Spheribond ODS 2 ( $5 \mu \mathrm{M}, 125 \times 4 \mathrm{~mm}$, Bischoff) column under reversed phase conditions, applying a linear gradient of eluents (buffer $\mathrm{A}: \mathrm{H}_{2} \mathrm{O}, 0.1 \%$ TFA; buffer B: acetonitrile, $0.1 \%$ TFA) and a flow rate of $1 \mathrm{~mL} / \mathrm{min}$. The gradient started with $5 \%$ B for $2.5 \mathrm{~min}$, ramped up to $95 \%$ in $15 \mathrm{~min}$, remained at $95 \%$ for $3.5 \mathrm{~min}$, and finally ramped down to $5 \%$ in $2 \mathrm{~min}$. Carbamazepine was measured at $210 \mathrm{~nm}$ in a photodiode array detector (Varian ProStar 335) and identified by comparison of the spectra and retention time of an authentic standard (Sigma-Aldrich). Calibration curves were constructed from a set of carbamazepine standard solutions ranging from 0.25 to $12 \mathrm{mg} / \mathrm{L}(1.04-50 \mu \mathrm{M})$. Chromatograms were analyzed using MS Workstation version 6.9.3 (Varian).

\section{ISOLATION OF CULTIVABLE ENDOPHYTIC BACTERIA FROM Phragmites australis PLANTS EXPOSED TO CARBAMAZEPINE}

After treatment with $5 \mathrm{mg} / \mathrm{L}$ carbamazepine for 9 days, roots, rhizomes, and stems were collected from different plants, washed with tap water to remove attached perlite and soil particles and mixed subsequently to constitute three independent samples (root, rhizome, and stem). Samples were separately sliced into $2-3 \mathrm{~cm}$ pieces, surface sterilized with a $2 \% \mathrm{NaClO}$ solution for $20 \mathrm{~min}$ under orbital shaking $(150 \mathrm{rpm})$ and rinsed three times with sterile water for $1 \mathrm{~min}$. They were then pestled in a glass mortar in $2 \mathrm{~mL}$ of sterile water. One milliliter aliquots were ten-fold diluted and $100 \mu \mathrm{L}$ of every dilution $\left(10^{-1}-10^{-6}\right.$ dilutions) were spread in duplicate onto R2A (Reasoner's 2A agar) and PDA (potato dextrose agar) plates and incubated at room temperature for 14 days. Carbamazepine was added to the plates at a final concentration of $10 \mu \mathrm{M}$. A $100 \mu \mathrm{L}$ sample of the third rinsing water was plated to verify the efficiency of sterilization. Distinct colony morphotypes were sub-cultured three times to ensure purity and cryopreserved for further characterization. 


\section{DNA EXTRACTION FROM BACTERIAL CULTURES AND AMPLIFICATION OF THE BACTERIAL 16S rRNA}

Genomic DNA from bacterial cultures was extracted using the FastDNA $^{\mathrm{TM}}$ SPIN kit for soil (MP Biomedicals) according to the recommendations of the manufacturer. Two to $3 \mathrm{~mL}$ of fresh cultures were used for this purpose. Universal primers 27FW ( $5^{\prime}$-AGAGTTTGATCCTGGCTCAG-3') and $1492 \mathrm{RV}$ were used to partially amplify the $16 \mathrm{~S}$ rRNA encoding gene from the endophytic bacteria. The $50 \mu \mathrm{L}$ PCR reaction mixture contained 100-200 ng of extracted DNA, $1 \times$ Top Taq buffer, $200 \mu \mathrm{M}$ of each dNTP, $200 \mathrm{pM}$ of each primer and 1.25 U of Top Taq polymerase (Qiagen). After initial denaturation at $94^{\circ} \mathrm{C}$ for $5 \mathrm{~min}$, each thermal cycling consisted of $1 \mathrm{~min}$ denaturation at $94^{\circ} \mathrm{C}, 1 \mathrm{~min}$ annealing at $52^{\circ} \mathrm{C}$ and 1.5 min elongation at $72^{\circ} \mathrm{C}$. After 35 cycles, a final extension step was performed at $72^{\circ} \mathrm{C}$ for $10 \mathrm{~min}$. PCR products were separated by electrophoresis on $1 \%$ agarose gels. Bands corresponding to approx. $1450 \mathrm{bp}$ were excised and purified using the NucleoSpin ${ }^{\circledR}$ Gel and PCR clean-up kit (Macherey-Nagel) according to the manufacturer's protocol. The purified PCR products were sequenced using the primers 16S-27f, 16S-609f, 16S-907R, and 16S-1492R in an ABI 3730 48-capillary sequencer (Applied Biosystems). PCR reactions for the sequencing were performed using the BigDye ${ }^{\circledR}$ Terminator v3.1 cycle sequencing kit (Life Technologies) following the instructions of the supplier.

\section{PHYLOGENETIC ANALYSIS OF Phragmites australis ENDOBACTERIA}

The identification of phylogenetic neighbors was initially carried out by the BLASTN (Altschul et al., 1997) program against the database containing type strains with validly published prokaryotic names and representatives of uncultured phylotypes (Kim etal., 2012). The top thirty sequences with the highest scores were then selected for calculation of pairwise sequence similarity using global alignment algorithm (Myers and Miller, 1988), which was implemented at the EzTaxon server (http://www.ezbiocloud.net/eztaxon; Kim et al., 2012).

The evolutionary history was inferred using the neighborjoining method (Saitou and Nei, 1987). Phylogenetic analysis was performed using the bootstrap method (2000 replicates; Felsenstein, 2009). Evolutionary distances were computed using the maximum composite likelihood method (MEGA, Tamura et al., 2004). Evolutionary analyses were conducted in MEGA6 (Tamura et al., 2013).

\section{CARBAMAZEPINE REMOVAL FROM LIOUID CULTURES BY Phragmites australis ENDOBACTERIA}

Bacterial isolates were tested for carbamazepine removal in liquid cultures. Cells were initially grown from the agar plates in $5 \mathrm{~mL}$ of Luria-Bertani (LB) medium until saturation and then $100 \mu \mathrm{L}$ were transferred to either $5 \mathrm{~mL}$ of fresh $\mathrm{LB} / 10$ medium containing $50 \mu \mathrm{M}$ of carbamazepine or $5 \mathrm{~mL}$ of fresh $\mathrm{AB}$ minimal medium (per liter: $2 \mathrm{~g}$ ammonium sulfate, $6 \mathrm{~g}$ sodium phosphate dibasic, $3 \mathrm{~g}$ potassium phosphate monobasic, $3 \mathrm{~g}$ sodium chloride, $1 \mathrm{~mL}$ calcium chloride $0.1 \mathrm{M}, 1 \mathrm{~mL}$ magnesium chloride $1.0 \mathrm{M}$ and $1 \mathrm{~mL}$ ferric chloride $0.003 \mathrm{M}$ ) containing carbamazepine as sole carbon source $(0.4 \mathrm{mM})$. Controls without inoculum were prepared using $5 \mathrm{~mL}$ of the corresponding sterile fresh media supplemented with the corresponding concentration of carbamazepine. All $5 \mathrm{~mL}$ prepared cultures and controls were incubated for 5 days at $28^{\circ} \mathrm{C}$ under orbital shaking (150 rpm). Cultures containing different final cell numbers were then centrifuged at $8000 \mathrm{rpm}$ for $10 \mathrm{~min}$. One milliliter of the supernatant was transferred to a new tube and frozen at $-20^{\circ} \mathrm{C}$. Carbamazepine concentration was determined by HPLC after thawing each sample and filtering it with a $0.45 \mu \mathrm{m}$ pore size filter.

\section{PLANT GROWTH PROMOTION TRAITS DETERMINATION IN ENDOPHYTIC BACTERIA}

Phosphate solubilization was determined by the appearance of a clear halo on Pikovskaya's agar plates after 3 days of incubation at $28^{\circ} \mathrm{C}$. Bacterial strains were streaked onto Pikovskaya's agar medium containing (per liter): $0.5 \mathrm{~g}$ yeast extract, $10 \mathrm{~g}$ glucose, $5 \mathrm{~g}$ calcium phosphate $\left[\mathrm{Ca}_{3}\left(\mathrm{PO}_{4}\right)_{2}\right], 0.5 \mathrm{~g}$ ammonium sulfate $\left[\left(\mathrm{NH}_{4}\right)_{2} \mathrm{SO}_{4}\right], 0.2 \mathrm{~g}$ potassium chloride $(\mathrm{KCl}), 0.1 \mathrm{~g}$ magnesium sulfate $\left(\mathrm{MgSO}_{4} .7 \mathrm{H}_{2} \mathrm{O}\right), 0.0001 \mathrm{~g}$ manganese sulfate $\left(\mathrm{MnSO}_{4} \cdot \mathrm{H}_{2} \mathrm{O}\right), 0.0001 \mathrm{~g}$ ferrous sulfate $\left(\mathrm{FeSO}_{4} .7 \mathrm{H}_{2} \mathrm{O}\right)$ and $15 \mathrm{~g}$ agar. Strains that induced a clear zone around the colonies were considered as positive.

Bacterial isolates were assayed for siderophore production on Chrome azurol S agar medium as described by Alexander and Zuberer (1991). Chrome azurol S agar plates were prepared, spot inoculated with bacterial isolates $\left(10 \mu \mathrm{l}\right.$ of $\left.10^{6} \mathrm{CFU} / \mathrm{ml}\right)$ and incubated at $28^{\circ} \mathrm{C}$ for $72 \mathrm{~h}$. Development of a yellow-orange halo around the colonies was considered as positive for siderophore production.

Indole acetic acid production was detected according to Bano and Musarrat (2003). The isolates were inoculated in LB medium supplemented with $0.5 \%$ glucose and $500 \mu \mathrm{g} / \mathrm{mL}$ tryptophan and incubated at $28^{\circ} \mathrm{C}$ for $48 \mathrm{~h}$. The cultures were centrifuged at $10000 \mathrm{rpm}$ for $15 \mathrm{~min}$ and $2 \mathrm{~mL}$ of the supernatant were transferred to a fresh tube to which $100 \mu \mathrm{L}$ of $10 \mathrm{mM}$ orthophosphoric acid and $4 \mathrm{~mL}$ of the Salkowski reagent $(1 \mathrm{~mL}$ of $0.5 \mathrm{M}$ ferrous chloride in $50 \mathrm{~mL}$ of $35 \%$ perchloric acid) were added. The mixture was incubated at room temperature for $25 \mathrm{~min}$ and the absorbance of pink color developed was read at $530 \mathrm{~nm}$. The IAA concentration in cultures was calculated from a calibration curve of pure IAA (Biochemica) solutions ranging from 10 to $50 \mu \mathrm{g} / \mathrm{mL}$.

\section{RESULTS}

\section{CARBAMAZEPINE UPTAKE IN PLANTS}

The capacity of Phragmites australis to take up carbamazepine was investigated under semihydroponic conditions. Adult plants were grown individually in pots containing perlite and treated with $5 \mathrm{mg} / \mathrm{L}(21.16 \mu \mathrm{M})$ of carbamazepine at $t=0$. The initial carbamazepine concentration determined by HPLC was $17.84 \mu \mathrm{M}$ in the control pots and $17.52 \mu \mathrm{M}$ in the plant samples.

When young reed plants were observed to $5 \mathrm{mg} / \mathrm{L}$ carbamazepine in the medium for 9 days, rapid uptake of the substance was observed within the first $24 \mathrm{~h}$ (Figure 1). Compared to controls without plants, where $5 \%$ of the compound was lost, $35 \%$ of carbamazepine disappeared from pots with plants. After 4 and 9 days, this initial rate of uptake decreased, but still significant amounts were taken up into the plant. After 4 days $66 \%$ were removed, and after 9 days only $10 \%$ were left, whereas the concentration 


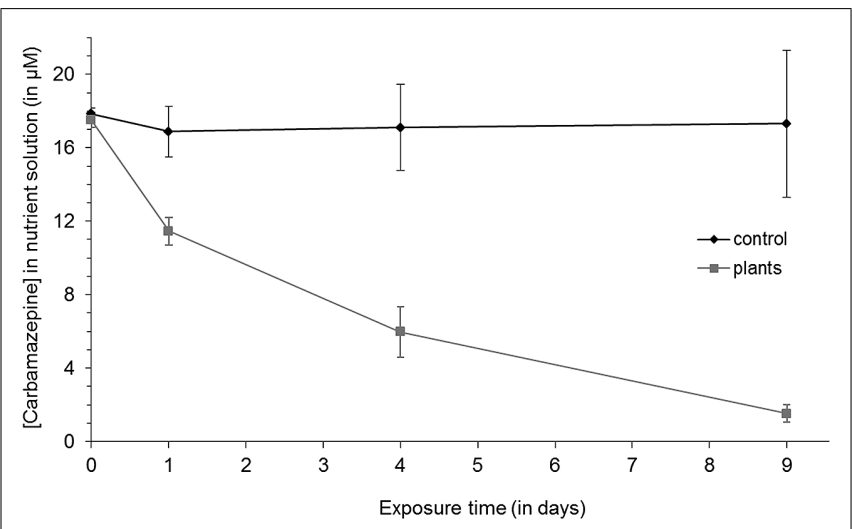

FIGURE 1 | Carbamazepine removal from the media by Phragmites australis at different exposure times. Vertical error bars represent means $\pm \mathrm{SD}(n=3)$

in the control pots remained constant. No visual signs of toxicity were detected in Phragmites australis. This high uptake led to the assumption that plant and endophyte based mechanisms jointly would favor the removal of the recalcitrant chemical. Therefore, endophytic bacteria were extracted from these exposed plants following standard methods.

\section{ISOLATION OF ENDOPHYTIC BACTERIA}

Extracts were prepared from different plant tissues (stems, roots, and rhizomes) after surface sterilization. No colonies grew on plates inoculated with the last rinsing water, indicating a good efficiency of the sterilization phase. After three subcultures, 41 isolates corresponding to distinct morphotypes were obtained and further characterized. Total DNA extracted from pure cultures was used to amplify bacterial 16S rRNA encoding genes. Sequencing of the fragments allowed taxonomic classification of the morphotypes, and finally 22 redefined distinct species could be identified (Table 1).

The diversity of culturable endophytic bacteria was estimated using $16 \mathrm{~S}$ rDNA sequencing. Phylogenetic analysis of the sequences revealed that the majority of isolates were affiliated with Proteobacteria $(72.7 \%$, Figures $2 \mathrm{~A}$ and 3 ). Other isolates belonged to Bacteroidetes (13.6\%), Actinobacteria (9.1\%), and Firmicutes (4.5\%). The genus Pseudomonas (Gamma-proteobacteria) was represented by the highest number of identified species $(22.7 \%$ of the total of isolates) followed by the genus Rhizobium (Alphaproteobacteria) with $13.6 \%$ and Acidovorax (Betaproteobacteria) with $9.1 \%$. Other members belonging to the phylum of Proteobacteria were identified as Achromobacter, Aquabacterium, Diaphorobacter, Eiseniicola, and Microvirgula (Betaproteobacteria) and Cedecea (Gammaproteobacteria) and represented $4.5 \%$. The rest of the isolates (54.6\%) were identified as members of different genera of Actinobacteria (Leifsonia, Kocuria), Bacteroidetes (Chryseobacterium, Flavobacterium, and Chitinophaga), and Firmicutes (Staphylococcus), each of them representing $4.5 \%$ of the total of isolates.

As far as the endophytic bacteria residing in the rhizomes are concerned, a similar distribution of phyla was found, with $76.9 \%$ of the isolates belonging to Proteobacteria, $15.4 \%$ to
Bacteroidetes and $7.7 \%$ to Actinobacteria (Figure 2B). No isolates from Firmicutes phylum were present in the rhizomes. Again, the genera Pseudomonas and Rhizobium represented the highest number of identified species with 23.1 and $15.4 \%$, respectively. The remaining rhizome endobacteria were identified as Leifsonia (Actinobacteria), Chitinophaga, and Chryseobacterium (Bacteroidetes), Acidovorax, Diaphorobacter, Eiseniiicola, and Microvirgula (Betaproteobacteria) and Cedecea (Gammaproteobacteria) with a representation of $7.7 \%$. The genera Achromobacter, Aquabacterium, Flavobacterium, and Kocuria were lacking among these isolates.

\section{CARBAMAZEPINE REMOVAL FROM LIOUID MEDIUM BY ENDOPHYTIC BACTERIA}

Bacterial isolates were tested for carbamazepine uptake from liquid media. When strains were grown for 5 days in presence of $50 \mu \mathrm{M}$ carbamazepine in small liquid LB/10 cultures, slight differences were recorded between the tested strains (Figure 4). Sterile controls were incubated under the same conditions to exclude potential effects of photooxidation, volatilization or adsorption to the tube walls on carbamazepine concentration. Only a few strains showed an uptake of the compound with rates ranging from 0.1 to $2.4 \%$. The highest uptake was found within Alphaproteobacteria (R. daejeonense with 2.45\%), Bacteroidetes (Chriseobacterium taeanense with $2.18 \%$ ), and Betaproteobacteria (A. mucicolens with $1.93 \%$ and D. nitroreducens with $1.78 \%$ ). One isolate affiliated to Pseudomonaceae family (Gammaproteobacteria) showed minor uptake (Pseudomonas moorei with $0.12 \%)$.

\section{PLANT GROWTH PROMOTING CHARACTERISTICS}

Phosphate solubilization, siderophore production, and auxin production were determined following qualitative or quantitative methods (Figure 4). All of the isolates had at least one of the PGP traits tested. Among them, $90 \%$ were able to produce indolacetic acid, whereas $59 \%$ were able to solubilize mineral phosphate and $54 \%$ secreted siderophores into the growth medium. Around 45\% of the isolates presented the three PGP traits tested. Most of these isolates belong to Gammaproteobacteria, Alphaproteobacteria, and Bacteroidetes. Whereas $45 \%$ were able to produce siderophores and solubilize phosphate, $59 \%$ were able to solubilize phosphate and produce IAA.

Indole acetic acid producers were present in all plant tissues, with values in most of the cases ranging between 2.08 and $3.41 \mu \mathrm{g} / \mathrm{mL}$. All isolates from rhizomes could produce IAA and among them, $R$. daejeonense showed an exceptionally high production of IAA $(23.04 \mu \mathrm{g} / \mathrm{mL})$. Siderophore producers were equally distributed between roots and rhizomes (69 and 67\% of root and rhizome isolates, respectively) whereas phosphate solubilizers were predominantly found in rhizomes (75\% of rhizomes isolates against $54 \%$ of root isolates). None of the Betaproteobacteria isolates could solubilize phosphate.

Ten isolates possessed the three PGP traits tested. This group comprised all members of Gammaproteobacteria (Pseudomonas veronii, Pseudomonas lini, Pseudomonas moorei, Pseudomonas arsenicoxydans, Pseudomonas coorrugata, and Cedecea davisae), two members from Alphaprotebacteria (R. radiobacter 
Table 1 | Taxonomic identification of endophytic bacteria from Phragmites australis plants exposed to carbamazepine based on the 16S rDNA sequence compared to validated type strains sequences deposited in the EzTaxon database.

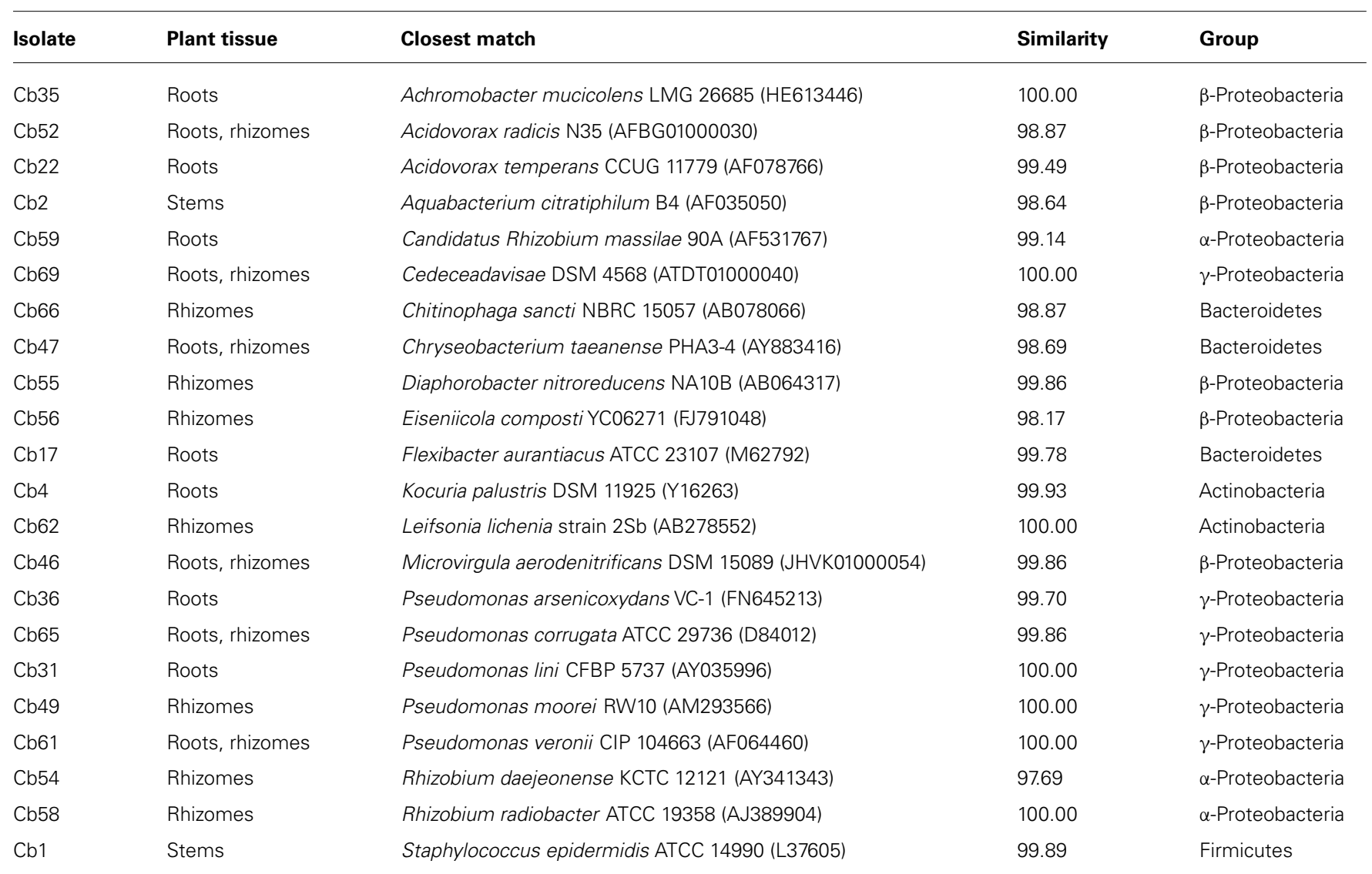

Numbers in parentheses represent the sequence accession numbers in GenBank.

and Candidatus R. massilae) and two members from Bacteroidetes (Chitinophaga sancti and Chriseobacterium taeanense).

\section{DISCUSSION \\ CARBAMAZEPINE UPTAKE BY COMMON REED}

Recently the uptake of carbamazepine into the wetland species Typha latifolia has been demonstrated (Dordio et al., 2011). In that paper, it was shown that within 7 days, $28 \%$ of a $2 \mathrm{mg} / \mathrm{L}$ (corresponding to $8.4 \mu \mathrm{M}$ ) initial concentration had been taken up by the plant. This amount is significantly lower than the uptake rate obtained here with reed at a higher initial concentration (removal of $90 \%$ after 9 days). Measurements of carbamazepine remaining in the control pots after 9 days did not reveal any adsorption to the perlite or vessel walls over time. Some studies have shown that the uptake of organic xenobiotics in Phragmites is correlated to the $\log \mathrm{K}_{\mathrm{OW}}$ and $\mathrm{pK}_{\mathrm{a}}$ of the xenobiotic and highest with compounds exhibiting $\log \mathrm{K}_{\mathrm{OW}}$ s between 1 and 3 (Schröder et al., 2008). Carbamazepine, with a $\log \mathrm{K}_{\mathrm{OW}}$ of 2.45 , is transported faster from roots to shoots in Phragmites than in Typha. Chazarenc et al. (2010) were not able to attribute any differences in evapotranspiration rates to the morphology of both species. Hence, other effects like plant biomass, ionic interactions, sorption etc. might be responsible for the more effective accumulation of carbamazepine in Phragmites tissues.
ENDOPHYTIC BACTERIA FROM PLANTS EXPOSED TO CARBAMAZEPINE Once inside the plant, the compound will be distributed in receiving tissues, predominantly the rhizomes. In order to clarify the potential impact of endophytic bacteria on the fate of carbamazepine we isolated extractable endobacteria from exposed Phragmites rhizomes and roots. Carbamazepine pressure was always maintained in order to stimulate growth of metabolizers and to identify potential beneficial microbiota among them.

Li et al. (2010) described the endophytic bacterial community in roots of Phragmites australis growing in a wetland in Beijing (They could identify 57 different endophytes, affiliated to Proteobacteria (78.9\%), Firmicutes (9\%), Bacteroidetes (6.6\%), Fusobacteria (2.4\%), and a few unidentified bacteria (3\%). Our results show a similar representation of the Proteobacteria (72.7\%), and an inverse tendency in Bacteroidetes (13.6\%) and Firmicutes (4.5\%) phyla. In addition, we found members affiliated to Actinobacteria. Fusobacteria were not present among our isolates, probably as they are obligatory anaerobic. Surprisingly, of 57 identified strains, only one was represented among our isolates. This result reveals a high speciation of the root microbiome driven by the plant in response to specific external conditions (in this case, a high concentration of carbamazepine). In fact, we do assume now that the plant (species, cultivar, age, health, and 
A

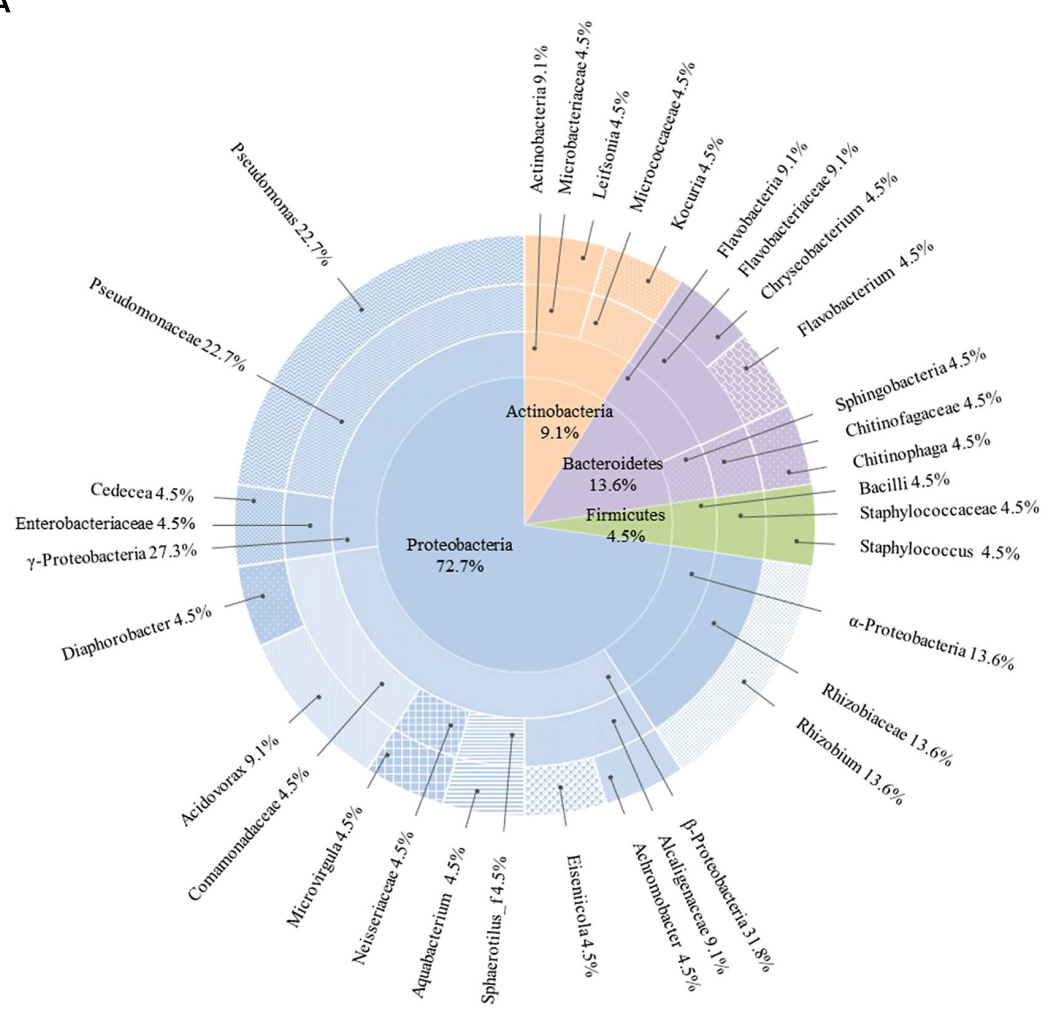

B

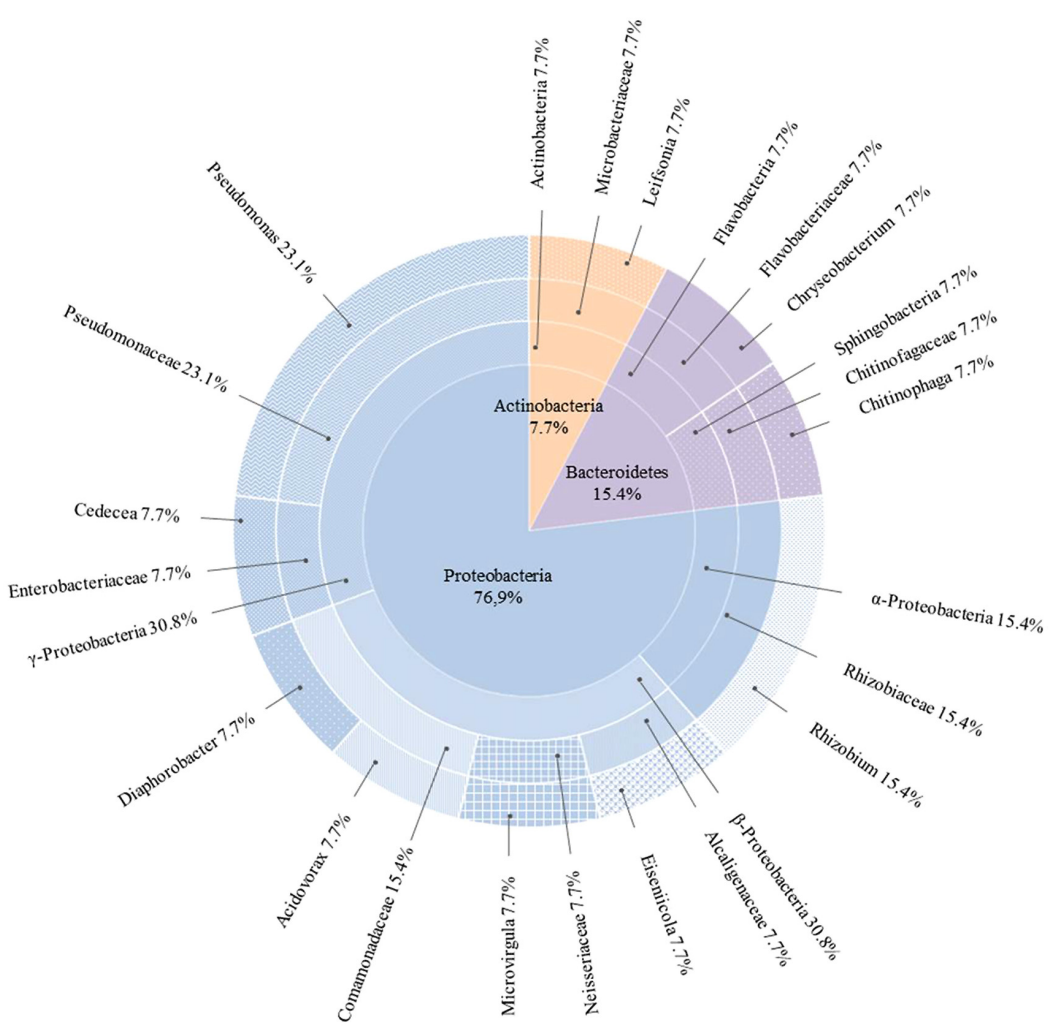

FIGURE 2 | Taxonomic breakdown of 16S rDNA sequences of total (A) and rhizomes (B) culturable endophytic bacterial community composition isolated from Phragmites australis plants exposed to $\mathbf{5} \mathbf{~ m g} / \mathbf{L}$ of carbamazepine for $\mathbf{9}$ days. The central pie shows phylum distribution in percentages and each outer ring breaks progressively down to lowest taxonomic levels (class, family, genera). 


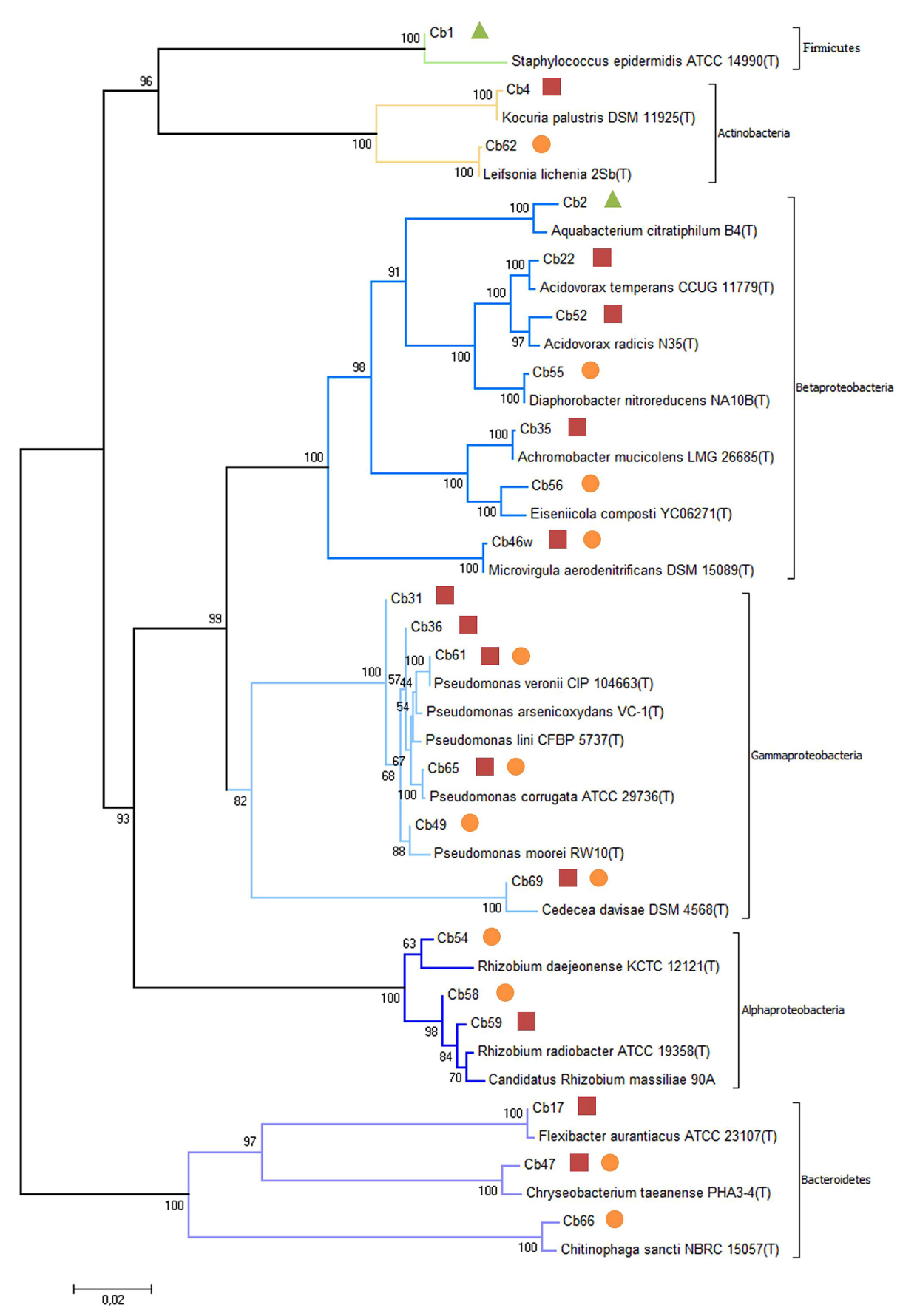

FIGURE 3 | Evolutionary relationships of isolates from reed plants exposed to carbamazepine based on 16S rDNA sequences obtained from all isolates and closely related sequences from EzTaxon database.

The tree is drawn to scale, with branch lengths in the same units as those of the evolutionary distances used to infer the phylogenetic tree. The percentage of replicate trees in which the associated taxa clustered together in the bootstrap test (2000 replicates) is shown next to the branches. The evolutionary distances were computed using the Maximum Composite Likelihood method. Endophytic bacteria isolated from stems ( $\Delta$ ), rhizomes (O) and roots ( $\square$. developmental stage) is not the only factor influencing microbial communities in the rhizosphere: a multitude of abiotic factors modulate structural and functional diversity of the rhizosphere microbiome, including soil properties, nutrient status, and climatic conditions (Berg et al., 2014). It has also been discussed that external factors imposed via the host plant such as soil, geographic factors, and anthropogenic management drive the overall structure and function of root microbiomes (Gaiero et al., 2013).

Pseudomonas (Gammaproteobacteria) was the most abundant genus among our isolates with $22.7 \%$ representation. Because 


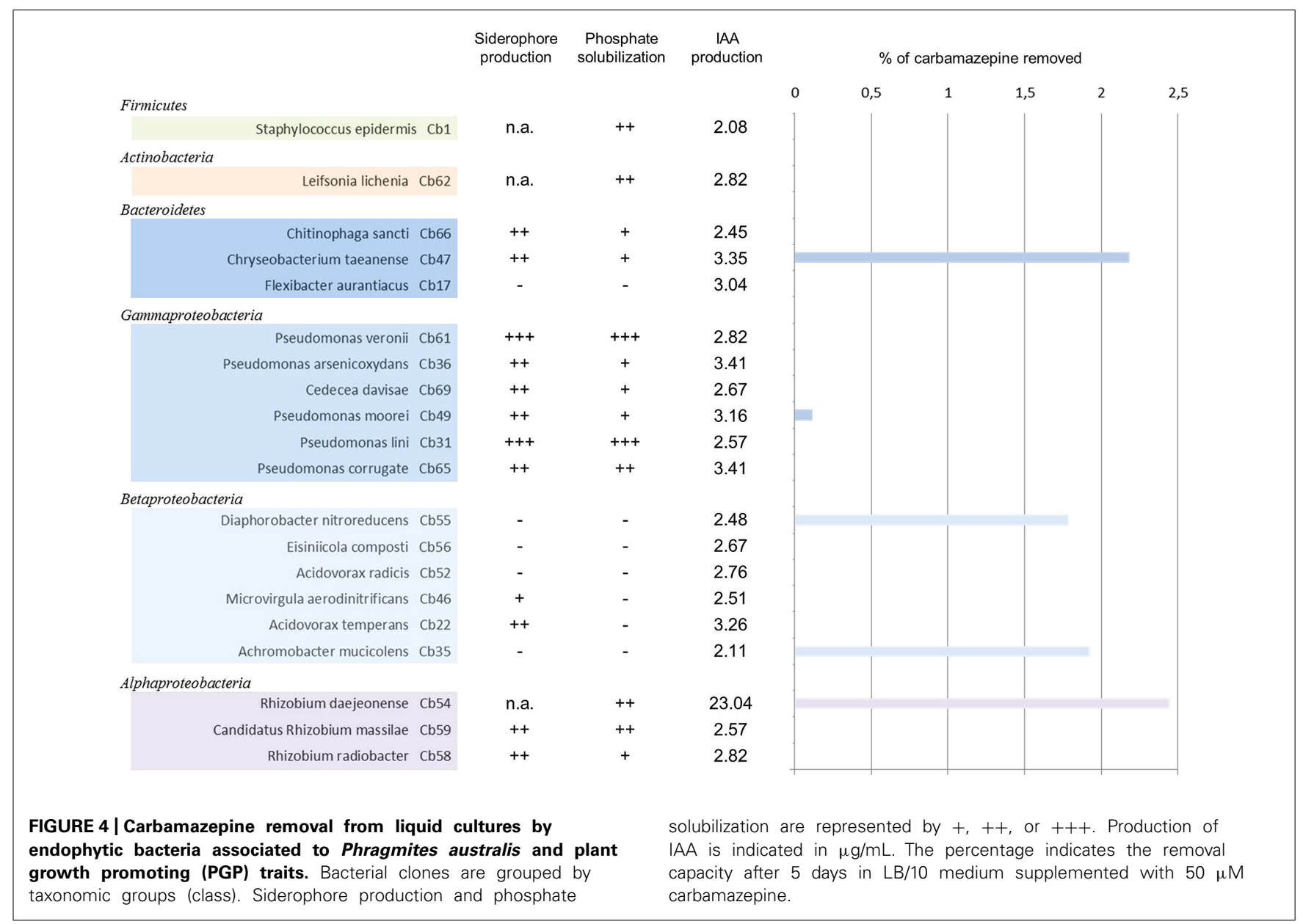

of the metabolic diversity in Pseudomonas, members of this genus have been used for the remediation of soils contaminated with organic pollutants such as hydrocarbons (Afzal et al., 2011; Andria et al., 2009), TCE (Weyens et al., 2009b, 2010), naphthalene (Germaine et al., 2009) toluene (Weyens et al., 2009b), and the herbicide 2,4-dichlorophenoxyacetic acid (Germaine et al., 2006). Furthermore, Pseudomonas has been studied as model for beneficial plant-microbe interaction. In the present study, one of the Pseudomonas isolates, Pseudomonas moorei, showed a slight carbamazepine removal from the liquid medium. All of the members affiliated to Pseudomonas exhibited all PGP traits tested, and two of them in particular. Pseudomonas linii is oxidasepositive, and denitrifies (Delorme et al., 2002) and Pseudomonas veronii possesses high oxidase and catalase activity, and denitrifies (Elomari et al., 1996). Thus, these isolates could be beneficial partners for the phytoremediation of organic pollutants, especially in constructed wetlands, were the removal of excess nitrogen is needed.

Rhizobium (Alphaproteobacteria) was the second genus with high representation (13.6\%) in the isolates. R. meliloti has been successfully applied in PAH removal observing an ability of this strain to stimulate the rhizosphere degrading microflora (Teng et al., 2011). Among our isolates, $R$. daejeonense showed the highest uptake of carbamazepine with $2.45 \%$ and additionally, the

highest production of IAA $(23.04 \mu \mathrm{g} / \mathrm{mL})$ and phosphate solubilization. A $R$. daejeonense strain has also been isolated from a cyanide-degrading bioreactor originally inoculated with an activated sludge from a municipal sewage treatment plant in Daejeon, Korea. It possesses catalase and oxidase activity, forms nodules in $M$. sativa and contains a nifH gene encoding a component of the nitrogenase complex (Quan et al., 2005). These characteristics make this strain one of the most promising candidates for inoculation studies.

Betaproteobacteria constitute a group widely represented among the isolates. Members of this class (together with Gammaproteobacteria) are important for plant development as they can oxidize ammonium to nitrite. In this group, A. xylosoxydans, and Burkholderia sp. have been used for phytoremediation of catechol and phenol (Ho etal., 2012) and toluene (Weyens et al., 2012), respectively. Among our isolates, A. mucicolens, and $D$. nitroreducens showed carbamazepine uptake but neither siderophore production nor phosphate solubilization. Nonetheless, A. mucicolens strains grow in the presence of $3 \% \mathrm{NaCl}$, reduce nitrate, and nitrite, denitrify, exhibit oxidase activity, and can grow anaerobicaly (Vandamme et al., 2013). D. nitroreducens, initially isolated from activated sludge, has interesting characteristics for phytoremediation, such as denitrification and catalase positive, and degradation of poly(3-hydroxybutyrate) 
and poly(3-hydroxybutyrate-co-hydroxyvalerate) under aerobic and anaerobic denitrifying conditions (Khan and Hiraishi, 2002).

Bacteroidetes represented the second most abundant phylum with $13.6 \%$ of the isolates. Chryseobacterium taeanense is the best strain in this group as reveals the presence of the three PGP traits tested and the uptake of carbamazepine. In terms of tissue compartmentation, there seems to be no strong difference between rhizomes and roots except for the absence of Firmicutes in rhizomes and a higher presence of phosphate solubilizers.

\section{METABOLISM OF CARBAMAZEPINE}

In summary, of 22 identified and isolated endophytic bacteria, seven isolates were chosen as best candidates for further inoculation studies. Out of these seven, three have both, carbamazepine degradation, and PGP properties ( $R$. daejeonense, Chryseobacterium taeanense, and Pseudomonas moorei), two exhibit strong PGP traits (Pseudomonas veronii and Pseudomonas lini) and two showed carbamazepine uptake but no PGP traits (D. nitroreducens and A. mucicolens). The relatively low rates of microbial carbamazepine uptake are in accordance with research published so far. Regarding microbial degradation studies, carbamazepine remains a notorious compound for its poor elimination, never showing removal levels higher than $30 \%$ across 20 studies examining lab and full scale subsurface flow, lab scale sequencing batch reactor, lab scale anaerobic digester, pilot, and lab scale membrane bioreactor, and full, pilot, and lab scale WWTP systems (Onesios et al., 2009). We believe that the role of plants may be decisive in this respect, and that cooperation between plants and associated bacteria might be necessary to boost elimination of problematic compounds such as carbamazepine. Plant transpiration will aid to enhance uptake of those compounds from the media, and endophytic bacteria will perform the first steps in detoxification, before typical plant detoxification mechanisms take over and convert the xenobiotic into non-toxic breakdown products. Either alone or in combination, the application of these strains to Phragmites australis or to other plant species could improve the plant's fitness in xenobiotic stress conditions and contribute to carbamazepine removal in constructed wetlands. Nevertheless, further inoculation studies need to be performed before implementation in WWTPs.

\section{CONCLUSION}

In this study, we have isolated endophytic bacteria from plants treated with $5 \mathrm{mg} / \mathrm{L}$ carbamazepine, a concentration 20-80 times higher than those usually found in municipal sewage water. Plants were able to remove $90 \%$ of the initial concentration from nutrient media within 9 days. The cultivable microbial community was characterized by sequencing of $16 \mathrm{~S}$ rRNAgene amplicons. Its degrading capacity was investigated in both diluted nutrient and minimal media. Plant growth promoting (PGP) traits such as phosphate solubilization, siderophore, and IAA production were analyzed. We found some interesting degrader isolates as well as some which contribute to the fitness of the plants under stress. These strains could serve in the future to improve in planta degradation of the antiepileptic drug in wetland-based waste water treatment plants. Further studies on this fruitful cooperation between plants and their endophytes are essential for an application at field scale.

\section{ACKNOWLEDGMENTS}

We would like to thank A. Kallenberg for her assistance with the English language editing of the manuscript. Special thanks to Monika Kugelmann for her support with plant cultivation. This work was funded by the Helmholtz cross programme "Sustainable Bioeconomy" and influenced by partnership with COST Action FA1103: Endophytes in Biotechnology and Agriculture.

\section{REFERENCES}

Afzal, M., Khan, Q. M., and Sessitsch, A. (2014). Endophytic bacteria: prospects and applications for the phytoremediation of organic pollutants. Chemosphere 117C, 232-242. doi: 10.1016/j.chemosphere.2014.06.078

Afzal, M., Yousaf, S., Reichenauer, T. G., Kuffner, M., and Sessitsch, A. (2011). Soil type affects plant colonization, activity and catabolic gene expression of inoculated bacterial strains during phytoremediation of diesel. J. Hazard. Mater. 186, 1568-1575. doi: 10.1016/j.jhazmat.2010.12.040

Alexander, D. B., and Zuberer, D. A. (1991). Use of chrome azurol S reagents to evaluate siderophore production by rhizosphere bacteria. Biol. Fertil. Soils 12, 39-45. doi: 10.1007/BF00369386

Altschul, S. F., Madden, T. L., Schäffer, A. A., Zhang, J., Zhang, Z., Miller, W., et al. (1997). Gapped BLAST and PSI-BLAST: a new generation of protein database search programs. Nucleic Acids Res. 25, 3389-3402. doi: 10.1093/nar/25. 17.3389

Andria, V., Reichenauer, T. G., and Sessitsch, A. (2009). Expression of alkane monooxygenase (alkB) genes by plant-associated bacteria in the rhizosphere and endosphere of Italian ryegrass (Lolium multiflorum L.) grown in diesel contaminated soil. Environ. Pollut. 157, 3347-3350. doi: 10.1016/j.envpol.2009. 08.023

Bano, N., and Musarrat, J. (2003). Isolation and characterization of phorate degrading soil bacteria of environmental and agronomic significance. Lett. Appl. Microbiol. 36, 349-353. doi: 10.1046/j.1472-765X.2003.01329.x

Berg, G., Grube, M., Schloter, M., and Smalla, K. (2014). Unraveling the plant microbiome: looking back and future perspectives. Front. Microbiol. 5:148. doi: 10.3389/fmicb.2014.00148

Carvalho, P. N., Basto, M. C. P., and Almeida, C. M. R. (2012). Potential of Phragmites australis for the removal of veterinary pharmaceuticals from aquatic media. Bioresour. Technol. 116, 497-501. doi: 10.1016/j.biortech.2012.03.066

Chazarenc, F., Naylor, S., Comeau, Y., Merlin, G., and Brisson, J. (2010). Modeling the effect of plants and peat on evapotranspiration in constructed wetlands. Int. J. Chem. Eng. 2010, 1-6. doi: 10.1155/2010/412734

Conkle, J. L., White, J. R., and Metcalfe, C. D. (2008). Reduction of pharmaceutically active compounds by a lagoon wetland wastewater treatment system in Southeast Louisiana. Chemosphere 73, 1741-8. doi: 10.1016/j.chemosphere.2008. 09.020

Daughton, C. G., and Ternes, T. A. (1999). Pharmaceuticals and personal care products in the environment: agents of subtle change? Environ. Health Perspect. 107(Suppl. 6), 907-938. doi: 10.1289/ehp.99107s6907

Delorme, S., Lemanceau, P., and Christen, R. (2002). Pseudomonas lini sp. nov., a novel species from bulk and rhizospheric soils. Int. J. Syst. Evol. Microbiol. 52, 513-523.

Dordio, A. V., Belo, M., Martins Teixeira, D., Palace Carvalho, A. J., Dias, C. M. B., Picó, Y., et al. (2011). Evaluation of carbamazepine uptake and metabolization by Typha spp., a plant with potential use in phytotreatment. Bioresour. Technol. 102, 7827-34. doi: 10.1016/j.biortech.2011.06.050

Elomari, M., Coroler, L., Hoste, B., Gillis, M., Izard, D., and Leclercl, H. (1996). DNA relatedness among Pseudomonas strains isolated from natural mineral waters and proposal of Pseudomonas veronii sp. nov. Int. J. Syst. Bacteriol. 46, 1138-1144. doi: 10.1099/00207713-46-4-1138

Fatta-Kassinos, D., Meric, S., and Nikolaou, A. (2011). Pharmaceutical residues in environmental waters and wastewater: current state of knowledge and future research. Anal. Bioanal. Chem. 399, 251-75. doi: 10.1007/s00216-010-4300-9

Felsenstein, J. (2009). Confidence limits on phylogenies: an approach using the bootstrap. Evolution 39, 783-791. doi: 10.2307/2408678 
Gaiero, J. R., McCall, C. A., Thompson, K. A., Day, N. J., Best, A. S., and Dunfield, K. E. (2013). Inside the root microbiome: bacterial root endophytes and plant growth promotion. Am. J. Bot. 100, 1738-1750. doi: 10.3732/ajb.12 00572

Germaine, K. J., Keogh, E., Ryan, D., and Dowling, D. N. (2009). Bacterial endophyte-mediated naphthalene phytoprotection and phytoremediation. FEMS Microbiol. Lett. 296, 226-234. doi: 10.1111/j.1574-6968.2009.01637.x

Germaine, K. J., Liu, X., Cabellos, G. G., Hogan, J. P., Ryan, D., and Dowling, D. N. (2006). Bacterial endophyte-enhanced phytoremediation of the organochlorine herbicide 2,4-dichlorophenoxyacetic acid. FEMS Microbiol. Ecol. 57, 302-310. doi: 10.1111/j.1574-6941.2006.00121.x

Heberer, T., Reddersen, K., and Mechlinski, A. (2002). From municipal sewage to drinking water: fate and removal of pharmaceutical residues in the aquatic environment in urban areas. Water Sci. Technol. 46, 81-88.

Herklotz, P. A., Gurung, P., Vanden Heuvel, B., and Kinney, C. A. (2010). Uptake of human pharmaceuticals by plants grown under hydroponic conditions. Chemosphere 78, 1416-1421. doi: 10.1016/j.chemosphere.2009.12.048

Hijosa-Valsero, M., Matamoros, V., Sidrach-Cardona, R., Martín-Villacorta, J., Bécares, E., and Bayona, J. M. (2010). Comprehensive assessment of the design configuration of constructed wetlands for the removal of pharmaceuticals and personal care products from urban wastewaters. Water Res. 44, 3669-3678. doi: 10.1016/j.watres.2010.04.022

Ho, Y.-N., Mathew, D. C., Hsiao, S.-C., Shih, C.-H., Chien, M.-F., Chiang, H.-M., et al. (2012). Selection and application of endophytic bacterium Achromobacter xylosoxidans strain F3B for improving phytoremediation of phenolic pollutants. J. Hazard. Mater. 219-220, 43-9. doi: 10.1016/j.jhazmat.2012.03.035

Holling, C. S., Bailey, J. L., Vanden Heuvel, B., and Kinney, C. A (2012). Uptake of human pharmaceuticals and personal care products by cabbage (Brassica campestris) from fortified and biosolids-amended soils. J. Environ. Monit. 14, 3029-3036. doi: 10.1039/c2em30456b

Huerta-Fontela, M., Galceran, M. T., and Ventura, F. (2011). Occurrence and removal of pharmaceuticals and hormones through drinking water treatment. Water Res. 45, 1432-1442. doi: 10.1016/j.watres.2010.10.036

Kang, J. W., Khan, Z., and Doty, S. L. (2012). Biodegradation of trichloroethylene by an endophyte of hybrid poplar. Appl. Environ. Microbiol. 78, 3504-3507. doi 10.1128/AEM.06852-11

Khan, S. T., and Hiraishi, A. (2002). Diaphorobacter nitroreducens gen nov, sp nov, a poly(3-hydroxybutyrate)-degrading denitrifying bacterium isolated from activated sludge. J. Gen. Appl. Microbiol. 48, 299-308. doi: 10.2323/jgam. 48.299

Kim, O.-S., Cho, Y.-J., Lee, K., Yoon, S.-H., Kim, M., Na, H., et al. (2012). Introducing EzTaxon-e: a prokaryotic $16 \mathrm{~S}$ rRNA gene sequence database with phylotypes that represent uncultured species. Int. J. Syst. Evol. Microbiol. 62, 716-21. doi: 10.1099/ijs.0.038075-0

Lapworth, D. J., Baran, N., Stuart, M. E., and Ward, R. S. (2012). Emerging organic contaminants in groundwater: a review of sources, fate and occurrence. Environ. Pollut. 163, 287-303. doi: 10.1016/j.envpol.2011.12.034

Li, A., Cai, R., Di, C., Qiu, T., Pang, C., Yang, J., et al. (2013). Characterization and biodegradation kinetics of a new cold-adapted carbamazepine-degrading bacterium, Pseudomonas sp. CBZ-4. J. Environ. Sci. (China) 25, 2281-2290. doi: 10.1016/S1001-0742(12)60293-9

Li, Y. H., Zhu, J. N., Zhai, Z. H., and Zhang, Q. (2010). Endophytic bacterial diversity in roots of Phragmites australis in constructed Beijing Cuihu wetland (China) FEMS Microbiol. Lett. 309, 84-93. doi: 10.1111/j.1574-6968.2010.02015.x

Matamoros, V., Arias, C., Brix, H., and Bayona, J. M. (2009). Preliminary screening of small-scale domestic wastewater treatment systems for removal of pharmaceutical and personal care products. Water Res. 43, 55-62. doi 10.1016/j.watres.2008.10.005

Matamoros, V., García, J., and Bayona, J. M. (2005). Behavior of selected pharmaceuticals in subsurface flow constructed wetlands: a pilot-scale study. Environ. Sci. Technol. 39, 5449-5454. doi: 10.1021/es050022r

Matamoros, V., García, J., and Bayona, J. M. (2008). Organic micropollutant removal in a full-scale surface flow constructed wetland fed with secondary effluent. Water Res. 42, 653-60. doi: 10.1016/j.watres.2007.08.016

Miège, C., Choubert, J. M., Ribeiro, L., Eusèbe, M., and Coquery, M. (2009). Fate of pharmaceuticals and personal care products in wastewater treatment plantsconception of a database and first results. Environ. Pollut. 157, 1721-1526. doi: 10.1016/j.envpol.2008.11.045
Myers, E. W., and Miller, W. (1988). Optimal alignments in linear space. Comput. Appl. Biosci. 4, 11-17. doi: 10.1093/bioinformatics/4.1.11

Onesios, K. M., Yu, J. T., and Bouwer, E. J. (2009). Biodegradation and removal of pharmaceuticals and personal care products in treatment systems: a review. Biodegradation 20, 441-66. doi: 10.1007/s10532-008-9237-8

Oulton, R. L., Kohn, T., and Cwiertny, D. M. (2010). Pharmaceuticals and personal care products in effluent matrices: a survey of transformation and removal during wastewater treatment and implications for wastewater management. J. Environ. Monit. 12, 1956-78. doi: 10.1039/c0em00068j

Park, N., Vanderford, B. J., Snyder, S. A., Sarp, S., Kim, S. D., and Cho, J. (2009). Effective controls of micropollutants included in wastewater effluent using constructed wetlands under anoxic condition. Ecol. Eng. 35, 418-423. doi: 10.1016/j.ecoleng.2008.10.004.

Peng, A., Liu, J., Gao, Y., and Chen, Z. (2013). Distribution of endophytic bacteria in Alopecurus aequalis Sobol and Oxalis corniculata L. from soils contaminated by polycyclic aromatic hydrocarbons. PLoS ONE 8:e83054. doi: 10.1371/journal.pone.0083054

Quan, Z.-X., Bae, H.-S., Baek, J.-H., Chen, W.-F., Im, W.-T., and Lee, S.-T. (2005). Rhizobium daejeonense sp. nov. isolated from a cyanide treatment bioreactor. Int. J. Syst. Evol. Microbiol. 55, 2543-2549. doi: 10.1099/ijs.0.63667-0

Saitou, N., and Nei, M. (1987). The neighbor-joining method: a new method for reconstructing phylogenetic trees. Mol. Biol. Evol. 4, 406-425.

Santos, I. J. S., Grossman, M. J., Sartoratto, A., Alexandre, N., and Durrant, L. R. (2012). Degradation of the recalcitrant pharmaceuticals carbamazepine and $17 \alpha$-ethinylestradiol by ligninolytic fungi. Chem. Eng. Trans. 27, 169-174. doi: 10.3303/CET1227029

Schröder, P., Daubner, D., Maier, H., Neustifter, J., and Debus, R. (2008). Phytoremediation of organic xenobiotics - Glutathione dependent detoxification in Phragmites plants from European treatment sites. Bioresour. Technol. 99, 7183-7191. doi: 10.1016/j.biortech.2007.12.081

Sheng, X., Chen, X., and He, L. (2008). Characteristics of an endophytic pyrenedegrading bacterium of Enterobacter sp. 12J1 from Allium macrostemon Bunge. Int. Biodeterior. Biodegrad. 62, 88-95. doi: 10.1016/j.ibiod.2007.12.003

Shenker, M., Harush, D., Ben-Ari, J., and Chefetz, B. (2011). Uptake of carbamazepine by cucumber plants - A case study related to irrigation with reclaimed wastewater. Chemosphere 82, 905-910. doi: 10.1016/j.chemosphere.2010. 10.052

Siciliano, S. D., Fortin, N., Mihoc, A., Wisse, G., Labelle, S., Beaumier, D. et al. (2001). Selection of specific endophytic bacterial genotypes by plants in response to soil contamination. Appl. Environ. Microbiol. 67, 2469-2475. doi: 10.1128/AEM.67.6.2469

Strauch, G., Möder, M., Wennrich, R., Osenbrück, K., Gläser, H. R., Schladitz, T., et al. (2008). Indicators for assessing anthropogenic impact on urban surface and groundwater. J. Soil Sediment. 8, 23-33. doi: 10.1065/jss2007.06.234

Tamura, K., Nei, M., and Kumar, S. (2004). Prospects for inferring very large phylogenies by using the neighbor-joining method. Proc. Natl. Acad. Sci. U. S. A. 101, 11030-11035. doi: 10.1073/pnas.0404206101

Tamura, K., Stecher, G., Peterson, D., Filipski, A., and Kumar, S. (2013). MEGA6: molecular evolutionary genetics analysis version 6.0. Mol. Biol. Evol. 30, 27252729. doi: 10.1093/molbev/mst197

Tanoue, R., Sato, Y., Motoyama, M., Nakagawa, S., Shinohara, R., and Nomiyama, K. (2012). Plant uptake of pharmaceutical chemicals detected in recycled organic manure and reclaimed wastewater. J. Agric. Food Chem. 60, 10203-10211. doi: $10.1021 /$ jf303142t

Teng, Y., Shen, Y., Luo, Y., Sun, X., Sun, M., Fu, D., et al. (2011). Influence of Rhizobium meliloti on phytoremediation of polycyclic aromatic hydrocarbons by alfalfa in an aged contaminated soil. J. Hazard. Mater. 186, 1271-1276. doi: 10.1016/j.jhazmat.2010.11.126

Ternes, T. A. (1998). Occurrence of drugs in German sewage treatment plants and rivers. Water Res. 32, 3245-3260. doi: 10.1016/S0043-1354(98)00099-2

Ternes, T. A., Bonerz, M., Herrmann, N., Teiser, B., and Andersen, H. R. (2007). Irrigation of treated wastewater in Braunschweig, Germany: an option to remove pharmaceuticals and musk fragrances. Chemosphere 66, 894-904. doi: 10.1016/j.chemosphere.2006.06.035

Tixier, C., Singer, H. P., Oellers, S., and Müller, S. R. (2003). Occurrence and fate of carbamazepine, clofibric acid, diclofenac, ibuprofen, ketoprofen, and naproxen in surface waters. Environ. Sci. Technol. 37, 1061-1068. doi: 10.1021/es0 $25834 \mathrm{r}$ 
Van Aken, B., Yoon, J. M., and Schnoor, J. L. (2004). Biodegradation of nitro-substituted explosives 2, 4, 6-trinitrotoluene, by a phytosymbiotic Methylobacterium sp. associated with poplar tissues (Populus deltoides x nigra DN34) Appl. Environ. Microbiol. 70, 508-517. doi: 10.1128/AEM.70.1.508

Vandamme, P., Moore, E. R. B., Cnockaert, M., De Brandt, E., Svensson-Stadler L., Houf, K., et al. (2013). Achromobacter animicus sp. nov., Achromobacter muci colens sp. nov., Achromobacter pulmonis sp. nov. and Achromobacter spiritinus sp. nov., from human clinical samples. Syst. Appl. Microbiol. 36, 1-10. doi: 10.1016/j.syapm.2012.10.003

Verlicchi, P., and Zambello, E. (2014). How efficient are constructed wetlands in removing pharmaceuticals from untreated and treated urban wastewaters? A review. Sci. Total Environ. 470-471, 1281-1306. doi: 10.1016/j.scitotenv. 2013.10.085

Weyens, N., Croes, S., Dupae, J., Newman, L., van der Lelie, D., Carleer R., et al. (2010). Endophytic bacteria improve phytoremediation of $\mathrm{Ni}$ and TCE co-contamination. Environ. Pollut. 158, 2422-2427. doi: 10.1016/j.envpol. 2010.04.004

Weyens, N., Schellingen, K., Beckers, B., Janssen, J., Ceulemans, R., van der Lelie, D., et al. (2012). Potential of willow and its genetically engineered associated bacteria to remediate mixed Cd and toluene contamination. J. Soils Sediments 13, 176-188. doi: 10.1007/s11368-012-0582-1

Weyens, N., van der Lelie, D., Artois, T., Smeets, K., Taghavi, S., Newman, L., et al. (2009a). Bioaugmentation with engineered endophytic bacteria improves contaminant fate in phytoremediation. Environ. Sci. Technol. 43, 9413-9418. doi: $10.1021 /$ es $901997 z$

Weyens, N., Taghavi, S., Barac, T., van der Lelie, D., Boulet, J., Artois, T., et al. (2009b). Bacteria associated with oak and ash on a TCE-contaminated site: characterization of isolates with potential to avoid evapotranspiration of TCE. Environ. Sci. Pollut. Res. Int. 16, 830-843. doi: 10.1007/s11356-0090154-0

Wiegel, S., Aulinger, A., Brockmeyer, R., Harms, H., Löffler, J., Reincke, H., et al. (2004). Pharmaceuticals in the river Elbe and its tributaries. Chemosphere 57, 107-26. doi: 10.1016/j.chemosphere.2004.05.017
Winker, M., Clemens, J., Reich, M., Gulyas, H., and Otterpohl, R. (2010). Ryegrass uptake of carbamazepine and ibuprofen applied by urine fertilization. Sci. Total Environ. 408, 1902-1908. doi: 10.1016/j.scitotenv.2010.01.028

Wu, C., Spongberg, A. L., Witter, J. D., Fang, M., and Czajkowski, K. P. (2010). Uptake of pharmaceutical and personal care products by soybean plants from soils applied with biosolids and irrigated with contaminated water. Environ. Sci. Technol. 44, 6157-6161. doi: 10.1021/es1011115

Wu, C., Spongberg, A. L., Witter, J. D., and Sridhar, B. B. M. (2012). Transfer of wastewater associated pharmaceuticals and personal care products to crop plants from biosolids treated soil. Ecotoxicol. Environ. Saf. 85, 104-109. doi: 10.1016/j.ecoenv.2012.08.007

Yousaf, S., Afzal, M., Reichenauer, T. G., Brady, C. L., and Sessitsch, A. (2011). Hydrocarbon degradation, plant colonization and gene expression of alkane degradation genes by endophytic Enterobacter ludwigii strains. Environ. Pollut. 159, 2675-2683. doi: 10.1016/j.envpol.2011.05.031

Conflict of Interest Statement: The authors declare that the research was conducted in the absence of any commercial or financial relationships that could be construed as a potential conflict of interest.

Received: 30 November 2014; accepted: 01 February 2015; published online: 20 February 2015.

Citation: Sauvêtre A and Schröder P (2015) Uptake of carbamazepine by rhizomes and endophytic bacteria of Phragmites australis. Front. Plant Sci. 6:83. doi: $10.3389 / f p l s .2015 .00083$

This article was submitted to Plant Biotechnology, a section of the journal Frontiers in Plant Science.

Copyright (c) 2015 Sauvêtre and Schröder. This is an open-access article distributed under the terms of the Creative Commons Attribution License (CC BY). The use, distribution or reproduction in other forums is permitted, provided the original author(s) or licensor are credited and that the original publication in this journal is cited, in accordance with accepted academic practice. No use, distribution or reproduction is permitted which does not comply with these terms. 